\title{
Investigation of the properties of a 3-level broadband antireflective struc- ture on silicon by THz time-domain spectroscopy
}

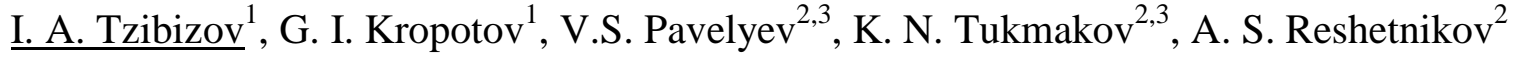 \\ ${ }^{1}$ Tydex LLC, 16, Domostroitelnaya st., 194292, St. Petersburg, Russia \\ ${ }^{2}$ Samara University, 34, Moskovskoe shosse, Samara, 443086, Russian Federation \\ ${ }^{3}$ Image Processing Systems Institute of the Russian Academy of Sciences, 151, Molodogvardejskaya st., Samara, 443001, \\ Russian Federation
}

The realization of a broadband antireflective coating in the $\mathrm{THz}$ range has been an urgent problem for many years. At present, only narrow-band antireflection coatings made on the basis of a single-layer coating are commercially available [1].

Here we want to present the results of the study of properties of a 3-level broadband antireflective (BBAR) structure on low-resistance silicon by $\mathrm{THz}$ time-domain spectroscopy (THz-TDS). BBAR structure was developed as a part of the manufacturing of a broadband $\mathrm{THz}$ radiation absorber, which can be used as a sensitive element of $\mathrm{THz}$ radiation detectors [2].

Since low-resistance silicon has a high absorption in the $\mathrm{THz}$ range, it was decided to use it as a substrate for a THz. To increase the amount of absorption, it is necessary to reduce losses associated with Fresnel reflection. For this, it was decided to create an antireflection coating on one side of the silicon substrate $[3,4]$.

To provide broadband antireflection effect, on the one side of the substrate a 3-level structure has been realized by use of reactive ion etching (Bosch process) $[3,5]$.

Sample device was fabricated from p-type $\rho=0.54$ Ohm $\mathrm{cm}$ silicon substrate with a diameter of $50 \mathrm{~mm}$ and thickness of $500 \mu \mathrm{m}$ (Fig. 1).

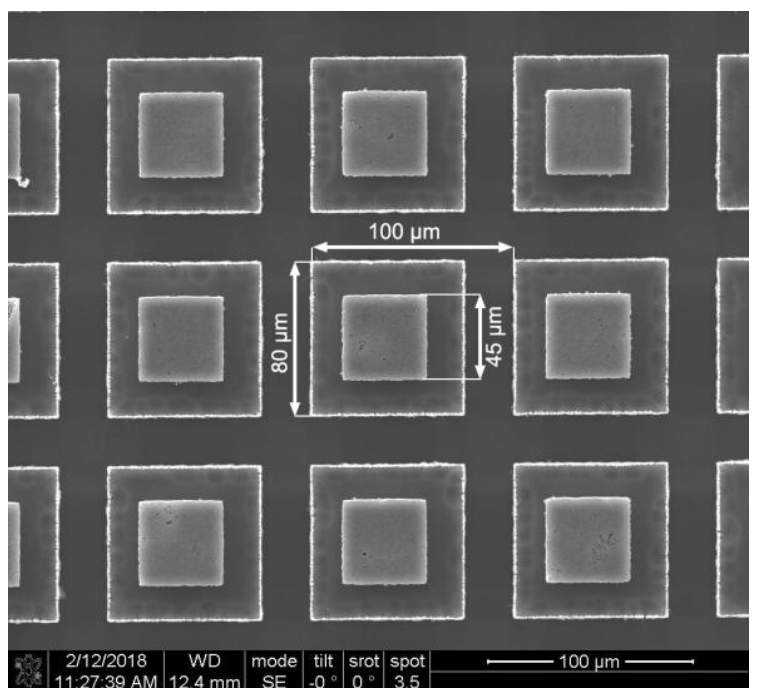

Fig. 1. Scanning electron microscope (SEM) images of the produced sample

To characterize the antireflection properties of the produced sample, the transmission and reflection measurements were carried out on the Tera K8 te- rahertz time-domain spectroscopy (THz-TDS) system (produced by Menlo Systems Gmbh).

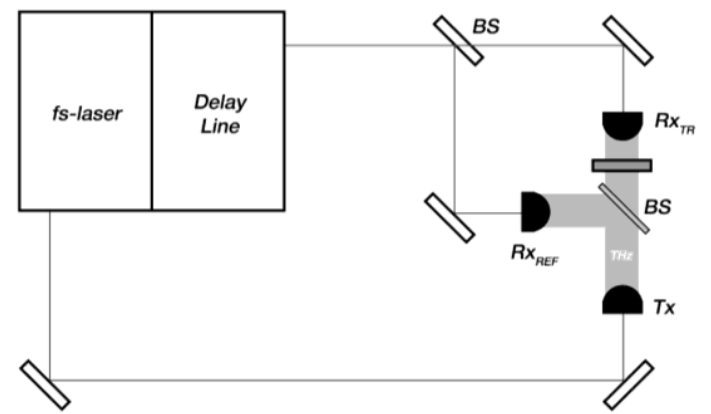

Fig. 2. Experimental setup

Tera K8 spectrometer operates in $0.2-2.5 \mathrm{THz}$ range. Spectral resolution $-5 \mathrm{GHz}$. The experimental setup is shown on Fig. 2. Both, bare silicon substrate and fabricated sample with 3-level antireflection structure were measured. Reflectance was measured under the normal angle of incidence. The value of Fresnel reflection decreased from $28-30 \%$ to less than $3 \%$ in $0.5-2 \mathrm{THz}$ range (Fig. 3).

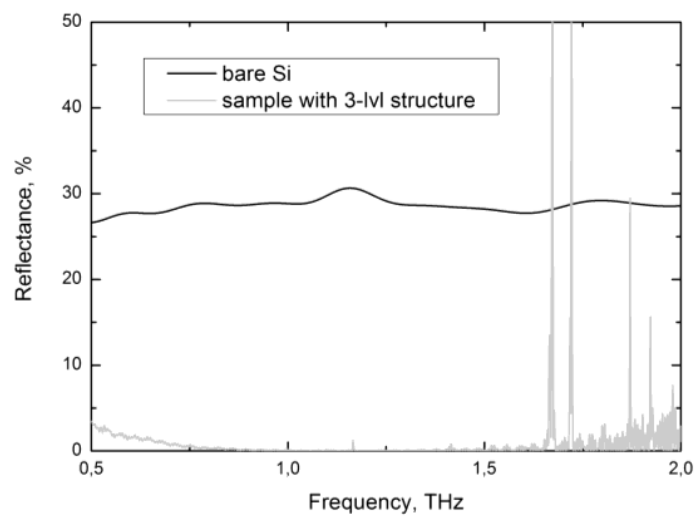

Fig. 3. Reflectance spectra of the fabricated sample

It can be concluded that fabricated structure can be used for reducing of reflection losses at the airsilicon interface of transmissive silicon optical elements in the broad range of the $\mathrm{THz}$ range frequencies. Also, it could be optimized for the certain frequency range.

\section{References}

1. A. J. Gatesman, J. Waldman, M. Ji, C. Musante, and S. Yngvesson, An Anti-Reflection Coating for Silicon Optics at Terahertz Frequencies // IEEE Microwave and Guided Wave Letters, 10, 7, pp $264-266$ (2010). 
2. J. Lehman, A. Sanders, L. Hanssen, B. Wilthan, J. Zeng, C. Jensen, Very black infrared detector from vertically aligned carbon nanotubes and electric-field poling of lithium tantalite // Nano Letters, 10, 3, P. 3261 (2010).

3. A.N. Agafonov, B.O. Volodkin, A.K. Kaveev, B.A. Knyazev, G.I. Kropotov, V.S. Pavel'ev, V.A. Soifer, K.N. Tukmakov, E.V.Tsygankova, Yu.Yu. Choporova, Silicon diffractive optical elements for high-power monochromatic terahertz radiation, Optoelectronics, Instrumentation and Data Processing, 49, pp. 189-195 (2013)
4. C. Brückner, T. Käsebier, B. Pradarutti, S. Riehemann et al., Broadband antireflective structures applied to high resistive float zone silicon in the $\mathrm{THz}$ spectral range, Optics Express, 17, 5, P. 3064 (2009).

5. A.N. Agafonov, B.O. Volodkin, D.G. Kachalov, B.A. Knyazev, G.I. Kropotov, K.N. Tukmakov, V.S. Pavelyev, D.I. Tsypishka, Yu.Yu. Choporova, A.K. Kaveev, Focusing of Novosibirsk Free Electron Laser (NovoFEL) radiation into paraxial segment, Journal of Modern Optics, 63, 11,pp. 1051-1054 (2016) 